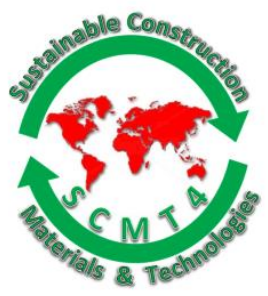

SCMT4

Las Vegas, USA, August 7-11, 2016

\title{
Fracture Behavior of High Volume Fly Ash-Self Consolidating Concrete
}

\author{
Hayder H. Alghazali ${ }^{1 a}$, and John. J. Myers ${ }^{1 b}$ \\ ${ }^{1}$ Missouri University of Science and Technology, Rolla, Missouri, USA, \\ ${ }^{1 a}$ Email: <hhac96@mst.edu>, ${ }^{1 b}$ Email:<jmyers@mst.edu>.
}

\begin{abstract}
Concrete sustainability can be improved by substituting recycled material for conventional material products. Incorporating fly ash in a concrete mix design supports cement and concrete producers in reducing the greenhouse gas emission associated with manufacturing cement and concrete. This study was conducted to develop a new cementitious material using high volume fly ash content. A replacement of more than 50\% was utilized to achieve sustainable design and significantly reduce a myriad of environmental impacts. Fracture energy of high volume fly ash-self consolidating concrete (HVFA-SCC) was examined. For this purpose, four mixes with $0 \%, 50 \%, 60 \%$, and $70 \%$ fly ash as cement replacements were studied. Hydrated lime was incorporated in the mixture to enhance the hydration process of the fly ash. In all, 16 fracture notched beams were investigated under three -point bending test. The rheological and mechanical properties of the HVFA-SCC were measured and evaluated. Furthermore, a comparison of the fracture energy provisions of different design codes and data reported in the literature was made.
\end{abstract}

\section{INTRODUCTION}

It is well known that concrete is the most widely used man-made material in the world after water. Undoubtedly, concrete shapes the built environment around us, from schools and housing to roads and bridges. Point in fact: concrete plays a critical role in the future success of sustainable development. Cement is an essential ingredient in the production of Portland cement concrete. Therefore, the production of cement poses several sustainability issues that need to be managed. Cement production emits $\mathrm{CO} 2$ and the quarrying of raw materials produces local impacts such as noise and dust. Also, the process that is employed to make the Portland cement is extremely energy intensive, consuming a large amount of resources. Cement manufacturing accounts for about $4.5 \%$ of the world's carbon dioxide emissions [Boden et al 2010]. Furthermore, the world's population continues to increase, which leads to an increase in construction. This will, in turn, also cause more cement to be manufactured. In this situation, for the cement and concrete industry to be sustainable in the future, a solution must be found to make concrete a more sustainable material. Various efforts are being employed to ensure that concrete becomes a more sustainable material. Sustainable technologies such as supplementary cementitious materials and recycled materials are some of the attractive options to achieve green concrete [Enad et al. 2013, Alghazali et al. 2015]. The most widely available supplementary cementitious material worldwide is fly ash, a by-product of coal-burning thermal power stations [Bilodeau 2000]. 
One way to further enhance the sustainability of concrete is by using self-consolidating concrete (SCC), especially in congested areas of steel. It is a highly workable concrete that can be consolidated into every corner of a framework, purely by the means of its own weight and without the need for mechanical consolidation [Daczko 2012]. SCC was developed in Japan in the early 1980s by Okamura and colleagues at Tokyo University [Ozawa et al. 1989]. The motivation for this development was a lack of skilled workers to place and consolidate concrete to make durable concrete structures [Daczko et al. 2006]. SCC's mixtures need high amounts of paste volume (higher cement content) to satisfy the flowability of SCC. Therefore, the current guidelines [EFNRC 2005] recommend using supplementary cementitious materials (SCMs) in SCC mixtures as a partial replacement of cement to enhance workability and control heat generation and cost efficiency. Traditionally, the fly ash used in structure concrete as a replacement or SCMs is limited to $15 \%$ to $25 \%$ cement replacement [ACI Committee 211]. An SCM exceeding this $50 \%$ level would be considered a high volume fly ash, and appropriate testing would have to be conducted to ensure the desired performance of the SCC.

High volume fly ash self-consolidating concrete (HVFA-SCC) is a self-consolidating concrete with the high amount of fly ash replacement exceeding a 50\% level. Bouzoubaa and Lachemi (2001) conducted a study to investigate the effect ash replacement had on the compressive strength and fresh properties of SCC with up to a $60 \%$ cement replacement. They observed that class F fly ash slightly enhances concrete workability. However, the early age compressive strength of such concrete was relatively low.

The mechanical properties of SCC have been studied from different points of view. Among the properties of hardened concrete, fracture behavior is a fundamental phenomenon in the design and safety assessment of structures especially large-scale structures [Bazant et al. 1998]. Previous researchers indicated a potential for decreasing fracture energy using concrete mixes containing very high levels of fly ash replacement [Brook et al. 1992; Padevet et al. 2011]. However, Arezoumandi and Volz (2013) investigated the effect fly ash replacement had on the fracture behavior of concrete. Different replacement levels, $0 \%, 30 \%, 50 \%$, and $70 \%$, of fly ash type $\mathrm{C}$ were used as cement replacement. They concluded that the mix with a higher level of fly ash replacement had higher fracture energy. Other researchers [Lam et al. 1998, Wong et al. 1999] also investigated the fracture behavior of concrete with high volumes of fly ash type F. The studies showed similar or higher fracture energies compared with conventional concrete mixes. Fly ash replacement at all levels that were studied increased the interfacial fracture energy.

The main purpose of this study is to examine the fracture behavior of SCC mixes with a high amount of fly ash replacement.

\section{EXPERIMENTAL STUDY}

Materials. Portland cement type I (confirming to the ASTM C-150) was used. A high calcium type C fly ash that meets the ASTM C-618 was used as a binder to produce the concrete. Hydrated lime type $\mathrm{S}$ was also used in this investigation to ensure a more complete hydration of the fly ash with a low cement content in the mix [Arezoumandi et al. 2013]. The specific gravities of cement, fly ash, and hydrated lime used were: $3.15,2.68$, and 2.5 , respectively. Natural sand with a 0.25 in $(6.35 \mathrm{~mm})$ maximum size, and 2.56 specific gravity was used as fine aggregate. The coarse aggregate used in this study was a crushed stone dolomite with a $3 / 8$ in $(10 \mathrm{~mm})$ maximum size and it had a 2.68 specific gravity and $1.56 \%$ absorption. A commercially available HRWRA was also used to maintain the workability of the HVFASCC.

Mixture proportions. HVFA-SCC was developed through two phases: optimizing the binder composition and optimizing the particle size distribution depending on the packing density of the aggregate skeleton. 
Optimization of binder composition. This phase aimed to optimizing the binder composition of the HVFA-SCC based on the mechanical properties, flow characteristics, cost, and durability properties in the cement mortar level. A total of 13 various binder compositions (with 2 replicated mixes) with different types and replacement levels of fly ash and hydrated lime were tested. The "design" blend propotions were generated using the Design-Expert ${ }^{\circledR}$ software program based on constraints imposed on the propotion limits of each individual component and were based on the literature and practical considerations. All the mixes had a 1:2.75 cementitous material to sand ratio and the water to cement ratio was kept constant $(\mathrm{w} / \mathrm{c}=0.35)$. All the tests were conducted acorrding to the ASTM guidlines. Based on the results obtained from the tests that conducted on all 13 mixes, all investigated mixtures were ranked using performance rank anaylsis. Figures 1,2, and 3 show the results in terms of the mixtures' compressive strength, drying shrinkage, and cost, respectively.

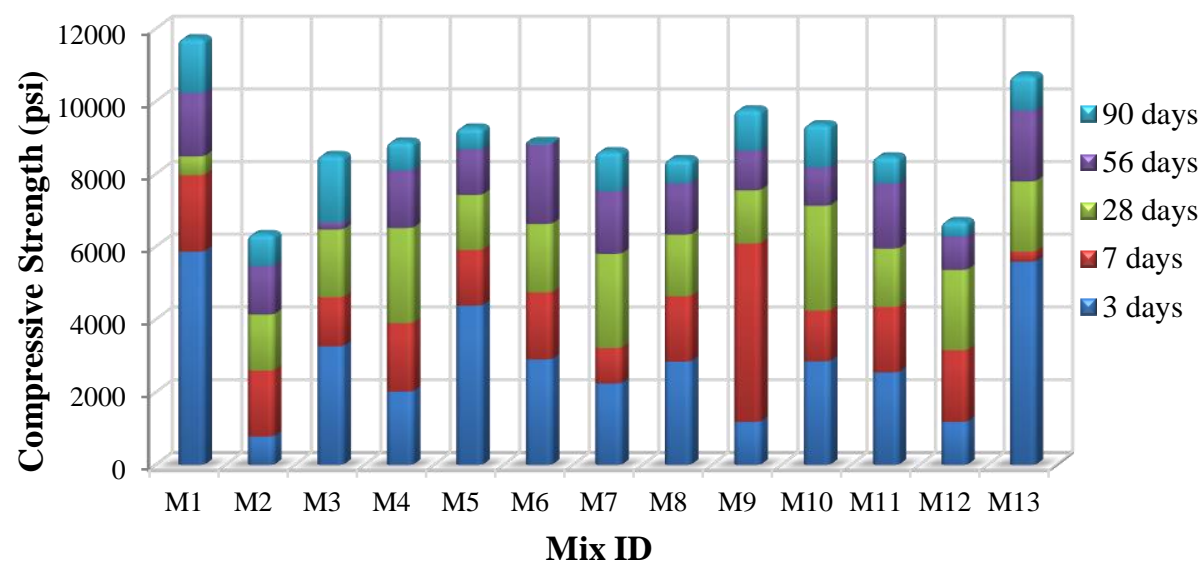

\begin{tabular}{|c|c|}
\hline Mix ID & proportion \\
\hline M1 & 100:00:00 \\
\hline M2 & $25: 68: 07$ \\
\hline M3 & 40:45:15 \\
\hline M4 & 37:59:04 \\
\hline M5 & 50:43:07 \\
\hline M6 & $35: 50: 15$ \\
\hline M7 & $37: 56: 07$ \\
\hline M8 & $37: 53: 10$ \\
\hline M9 & $45: 45: 10$ \\
\hline M10 & $35: 60: 05$ \\
\hline M11 & $35: 60: 05$ \\
\hline M12 & $25: 65: 10$ \\
\hline M13 & 50:50:00 \\
\hline
\end{tabular}

Figure 1. Compressive Strength of Different Binder Compositions

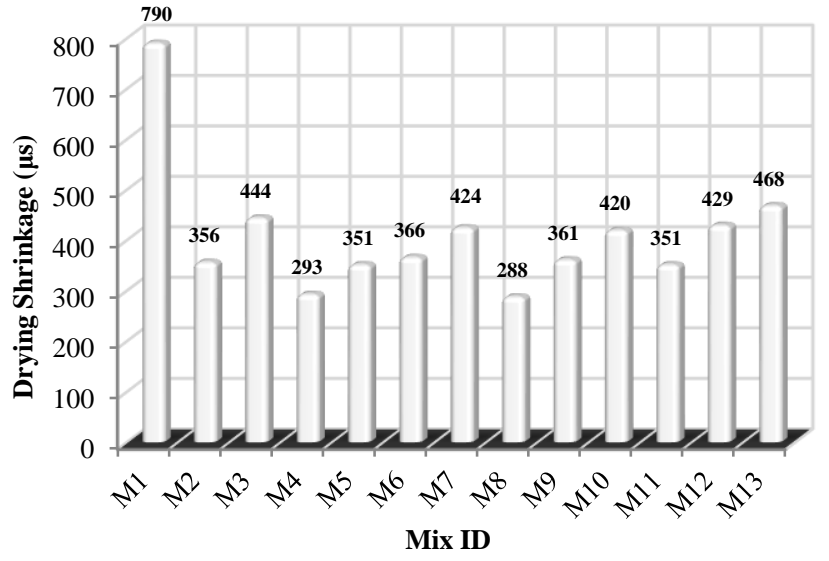

Figure 2. Drying Shrinkage of Different Binder Compositions.

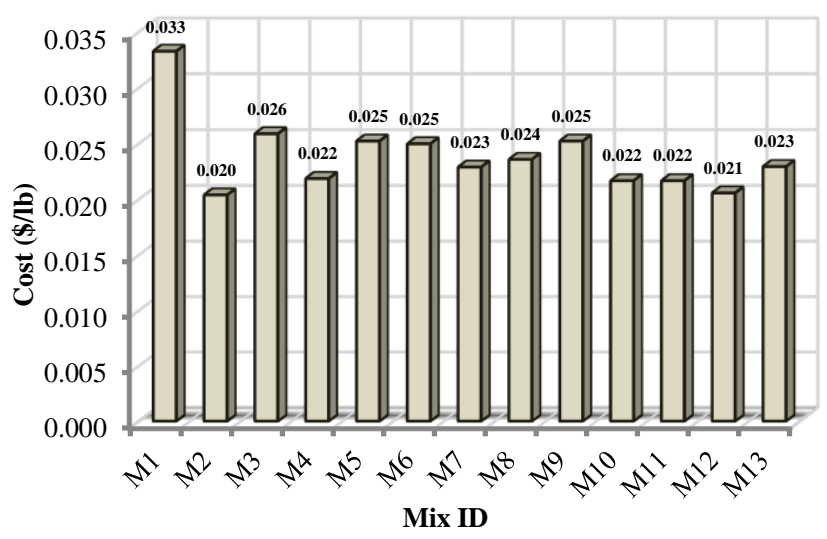

Figure 3. Materials Cost of Different Binder Compositions.

Table 1 summarizes the ranking of the investigated mixtures depending on the performance of each mix. The overall performances of the investigated mixtures were compared in terms of high performance to secure high compressive strength, low drying shrinkage, low cost, high flowability, and high durability. Weighted factors of 4, 3, and 2 were assigned to the compressive strength, cost, and drying shrinkage, respectively. The mini slump, flow table, surface resistivity, bulk resistivity, and unit weight were assigned a weighted factor of 1 . High numbers for the sums of rankings reflect better overall 
performances. From this primenary study that were initially investigated, ratios of $0 \%, 50 \%, 60 \%$, and $70 \%$ fly ash replacement were selected to illustrate incremental fly ash effect on fracture behavior of HVFA-SCC mixtures.

Table 1. Evaluation of Investigated Mortar using Performance Rank Analysis

\begin{tabular}{|c|c|c|c|c|c|c|c|c|c|c|}
\hline \multirow{2}{*}{$\begin{array}{c}\text { Mix } \\
\text { ID }\end{array}$} & \multirow{2}{*}{$\begin{array}{l}\text { Proportio } \\
\mathrm{n}^{*}\end{array}$} & \multicolumn{8}{|c|}{ Ranking } & \multirow{2}{*}{$\begin{array}{c}\text { Sum of } \\
\text { Ranking* } \\
*\end{array}$} \\
\hline & & f'c & $\begin{array}{c}\text { Drying } \\
\text { Shrinkage }\end{array}$ & $\begin{array}{l}\text { Flow } \\
\text { Table }\end{array}$ & $\begin{array}{c}\text { Mini } \\
\text { Slump }\end{array}$ & $\begin{array}{c}\text { Cost } \\
\text { Efficiency }\end{array}$ & $\begin{array}{c}\text { Unit } \\
\text { Weight }\end{array}$ & $\begin{array}{c}\text { Surface } \\
\text { Resistivit } \\
\text { y } \\
\end{array}$ & $\begin{array}{c}\text { Bulk } \\
\text { Resistivit } \\
\mathbf{y} \\
\end{array}$ & \\
\hline M1 & $\begin{array}{c}100: 00: 0 \\
0\end{array}$ & 13 & 1 & 5 & 12 & 1 & 12 & 13 & 13 & 99 \\
\hline M2 & $50: 43: 07$ & 1 & 9 & 1 & 3 & 13 & 11 & 1 & 1 & 77 \\
\hline M3 & $45: 45: 10$ & 6 & 3 & 2 & 7 & 2 & 13 & 9 & 9 & 67 \\
\hline M4 & $50: 50: 00$ & 5 & 12 & 3 & 10.5 & 9 & 2 & 8 & 7 & 94 \\
\hline M5 & $45: 45: 10$ & 11 & 11 & 10 & 7 & 3 & 3 & 10 & 11 & 106 \\
\hline M6 & $35: 50: 15$ & 8 & 7 & 8 & 10.5 & 5 & 10 & 3 & 3 & 93 \\
\hline M7 & $35: 60: 05$ & 3 & 5 & 11 & 5 & 8 & 6 & 6 & 5 & 73 \\
\hline M8 & $37: 53: 10$ & 7 & 13 & 12 & 13 & 6 & 9 & 4 & 6 & 112 \\
\hline M9 & $37: 59: 04$ & 10 & 8 & 9 & 7 & 4 & 8 & 12 & 12 & 104 \\
\hline M10 & $40: 45: 15$ & 9 & 6 & 6.5 & 4 & 10.5 & 4 & 11 & 10 & 104 \\
\hline M11 & $37: 56: 07$ & 4 & 10 & 6.5 & 1.5 & 10.5 & 5 & 5 & 4 & 85 \\
\hline M12 & $25: 65: 10$ & 2 & 4 & 4 & 9 & 12 & 7 & 2 & 2 & 74 \\
\hline M13 & $25: 68: 07$ & 12 & 2 & 13 & 1.5 & 7 & 1 & 7 & 8 & 97 \\
\hline
\end{tabular}

Optimization of particle size distribution of aggregate. The aim of this phase was to optimize the particle size distribution of the aggregate using experimental method (gyratory compactor) to maximize the packing density of aggregate [Khayat et al. 2014]. Also, by maximizing the packing density of aggregate, paste volume needed to fill the voids between aggregate particles can be minimized. Figure 1 shows the sieve analysis of both sand and crushed stone. A gyratory intensive compaction tester (ICT), shown in Figure 5, was employed to investigate the packing density of the aggregate. ICT Gyratory compaction is considered to be one of the best methods for evaluting packing density of solid particles. Based on the results from the expermintal packing density measurment, the optimum blended aggregate correspondes to the high packing density was used( $\mathrm{S} / \mathrm{CA}=45: 55)$.

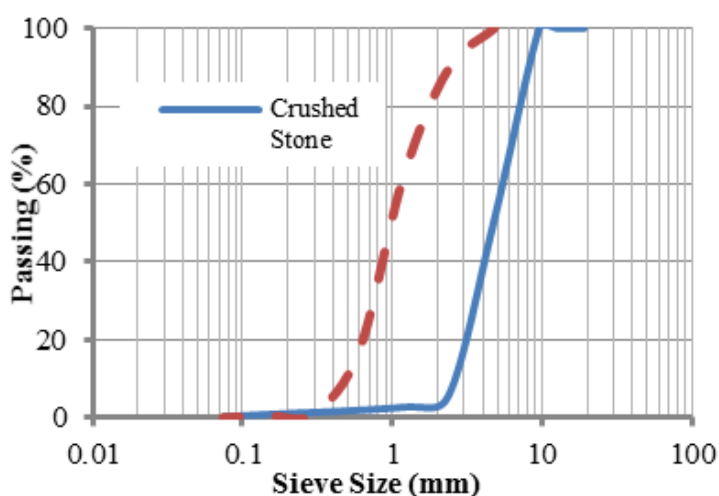

Figure 4. Grain Size Distribution of Fine and Coarse Aggregate.

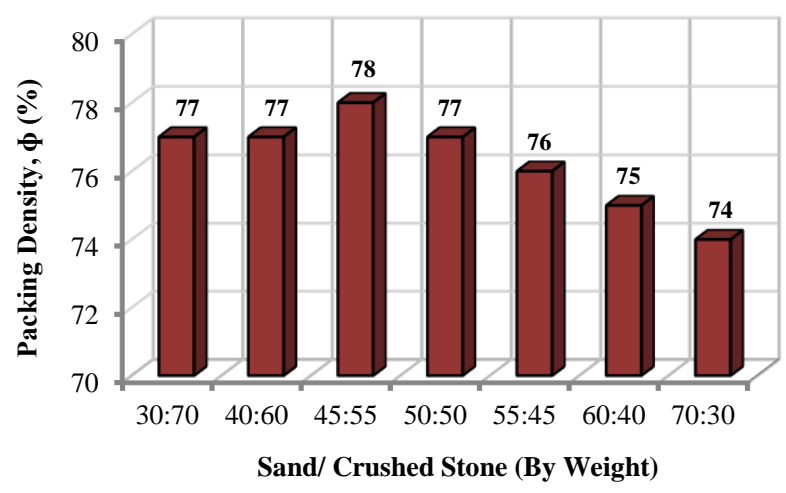

Figure 5. Effect of S/CA on Packing Density. 


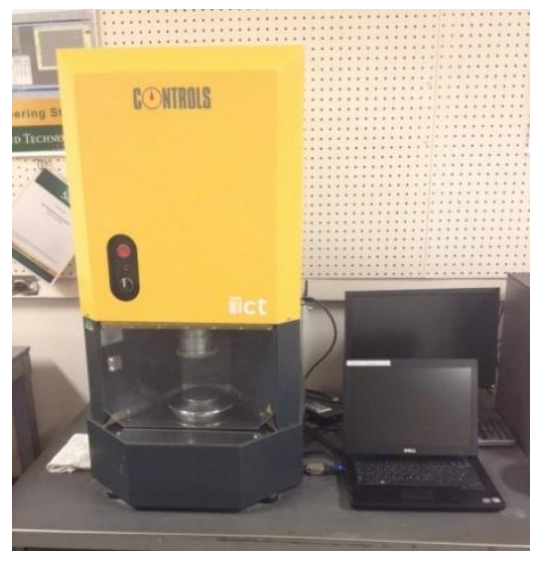

Figure 6. Gyratory Intensive Compaction Tester (ICT).

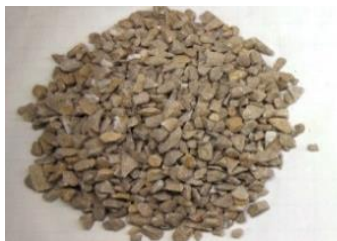

$3 / 8$ crushed stone

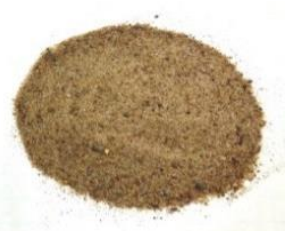

River Sand

Figure 7. Aggregate Types Used in this Study.

Mix design. The HVFA-SCC mixes were designed based on the results obtained from the two phase shown above. Table 2 summarizes the mixture proportions of HVFA-SCC mixtures with four binder compositions. The binder content and w/c were kept constant at $445 \mathrm{~kg} / \mathrm{m}^{3}\left(750 \mathrm{lb} / \mathrm{yd}^{3}\right)$ and 0.35 , respectively, for all HVFA-SCC mixtures. The HRWRA dosage was adjusted to secure the slump flow of $670 \pm 25 \mathrm{~mm}(26 \pm 1 \mathrm{in}$.).

Table 2. Mixture Proportion

\begin{tabular}{|c|c|c|c|c|c|c|c|c|}
\hline \multirow[t]{2}{*}{ Mix ID } & \multicolumn{7}{|c|}{ Mixture Composition $\left(\mathrm{kg} / \mathrm{m}^{3}\right)$} & \multirow{2}{*}{$\begin{array}{r}\text { HRWR } \\
\left(\mathrm{L} / \mathbf{m}^{3}\right)\end{array}$} \\
\hline & $\mathbf{C M}$ & Cement & Fly Ash & $\begin{array}{c}\text { Hydrated } \\
\text { Lime }\end{array}$ & $\mathbf{W} / \mathbf{C}$ & Sand & $\begin{array}{c}\text { Crushed } \\
\text { Stone }\end{array}$ & \\
\hline Control-SCC & 445 & 445 & 0 & 0 & 0.35 & 824 & 917 & 3.19 \\
\hline HVFA-SCC 50 & 445 & 223 & 191 & 31 & 0.35 & 824 & 916 & 4.20 \\
\hline HVFA-SCC 60 & 445 & 178 & 223 & 44 & 0.35 & 820 & 912 & 4.69 \\
\hline HVFA-SCC 70 & 445 & 133 & 254 & 58 & 0.35 & 817 & 908 & 4.60 \\
\hline
\end{tabular}

Fracture energy. Three-point bend tests were utilized on the notched beams to determine fracture energy in this study. In this method, recommended by technical committee RILEM 50-FMC, the fracture energy is defined as the work needed to create one unit area of a crack. As the beam is broken in two halves, the fracture energy can be computed by dividing the total dissipated energy by the ligament area as shown in Eq. 1. It is worth noting that this method in fracture mechanic texts is also known as the work-of-fracture method (WFM) or Hillerborg's method.

$$
G_{F}=\frac{W_{f}}{b\left(d-a_{0}\right)}
$$

where the term $\mathrm{W}_{\mathrm{f}}$ is the total energy dissipated in the test, and $\mathrm{b}, \mathrm{d}$, and $\mathrm{a}_{0}$ are the width, height, and the initial notch depth of the beam cross section, respectively.

Moreover, the brittleness of a material in the work of fracture method can be described as the characteristic length, which is related to the fracture process zone length that was introduced by Hillerborg et al. (1976) as: 


$$
l_{c h}=\frac{E_{c} G_{f}}{f_{t}^{2}}
$$

where $E_{c}$ and $f_{t}$ are the modulus of elasticity and the tensile strength, respectively. The lower the value of $1_{\mathrm{ch}}$, the more brittle the material.

In this study, the beam specimens measured $150 \mathrm{~mm}$ x $150 \mathrm{~mm}$ x $600 \mathrm{~mm}(6 \mathrm{in}$ x 6 in. $\mathrm{x} 24$ in.) with a span equal to $450 \mathrm{~mm}$ (18 in.). A notch-to-depth ratio of 0.25 was introduced in the center of each beam with a Teflon plate cast into the concrete as opposed to being saw cut after the concret hardened. The tests were displacement-controlled, and thus, a closed- loop servo electro controlled MTS machine was used at a loading rate of $0.12 \mathrm{~mm} / \mathrm{min}$. Figure 8 displays set up of the fracture energy specimens.

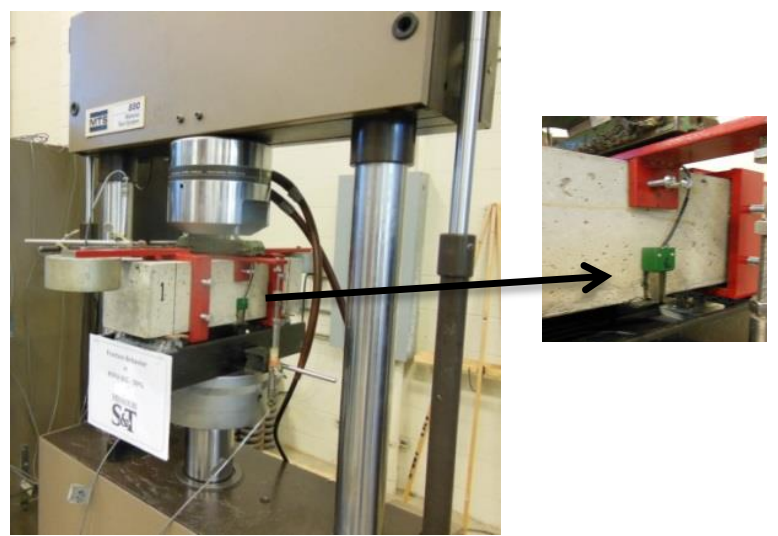

Figure 8. Test Setup of Fracture Energy Specimens.
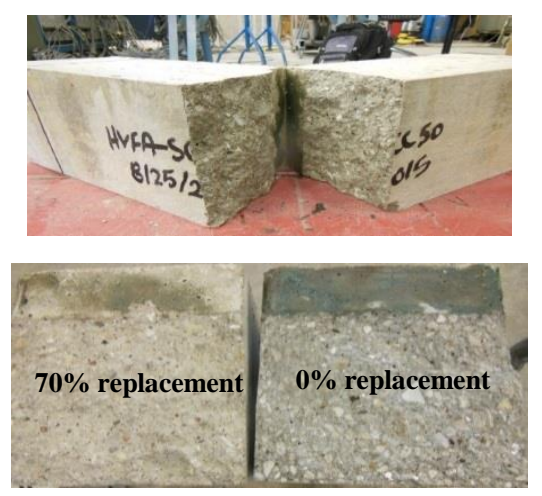

Figure 9. Fracture Surface Appearance.

\section{RESULTS AND DISCUSSION}

The following section illustrates the test results of this study and includes a brief discussion of the effect of HVFA-SCC on the fracture energy of concrete.

Fresh and hardened properties. The test results of slump flow, T50, J-Ring, L-Box, density, air content and temperature are presented in Table 3. The mixtures with HVFA exhibited better rheological properties than the $100 \%$ cement mixture. Mechanical properties including compressive strength, modulus of elasticity, and tensile splitting were measured according to ASTM specifications. The mix with a $70 \%$ mixture exhibited better mechanical properties than the mixes with 50 and $60 \%$ replacement levels because the increase in hydrated lime increased the hydration activity of the fly ash.

Table 3. Measured Rheological Properties.

\begin{tabular}{|l|c|c|c|c|c|}
\hline \multirow{2}{*}{ Property } & \multirow{2}{*}{ Specification } & \multicolumn{4}{c|}{ Mix ID } \\
\cline { 3 - 6 } & & Control-SCC & HVFA-SCC 50 & HVFA-SCC 60 & HVFA-SCC 70 \\
\hline Slump flow (mm) & ASTM C1611 & 686 & 660 & 660 & 673 \\
\hline T50 (Sec) & & 1 & 1.9 & 1.3 & 1.05 \\
\hline J-Ring (mm) & ASTM C1621 & 660 & 635 & 660 & 635 \\
\hline L-Box & & 0.85 & 0.8 & 1 & 0.8 \\
\hline Temperature (F) & ASTM C1064 & 70 & 80.4 & 83.5 & 83.3 \\
\hline Unit Weight (kg/m $\mathbf{3})$ & ASTM C231 & 2343 & 2313 & 2303 & 2252 \\
\hline Visual stability index (VSI) & ASTM C1611 & 1 & 0 & 0 & 0 \\
\hline Entrapped Air Content (\%) & ASTM C231 & 2.4 & 5 & 5 & 4.1 \\
\hline
\end{tabular}


Fracture energy. Fracture energy is actually the energy required to create a crack with in a unit area. The total energy is determined by measuring the area under a load-displacement curve according to Eq. 1. The results of the fracture energy tests for HVFA-SCC are presented in Table 4 along with the compressive strength, tensile strength, and modulus of elasticity at the time of testing. As seen before, fracture energy is directly related to the area under the load-displacement curve. Any error in the calculation of the area affects the determination of the energy. As seen in Table 4, all HVFA-SCC mixes exhibited higher brittleness than the 100\% cement mix. Also, included in Table 5 are the theoretical fracture energies based on the relationships proposed by Bazant and Becq-Giraudon and the CEB-FIP Model Code 2010. The expression proposed by Bazant and Becq- Giradon represents the relation between fracture energy and the major parameters of mix design based on an expansive collection of 238 previously collected results (see Eq. 3). CEB-FIP Model Code 2010, shown as Eq. 4, is only a function of compressive strength. As shown in Table 5, both the Bazant and CEB-FIP equations underestimated the fracture energies of HVFA-SCC with predicted values ranging from 40 to $90 \%$ of the test values.

$$
\begin{aligned}
G_{F} & =2.5 \alpha_{0}\left(\frac{f^{\prime} c}{0.051}\right)^{0.46}\left(1+\frac{d_{a}}{11.27}\right)^{0.22}\left(\frac{w}{c}\right)^{-0.33} \\
G_{F} & =73 f_{c m}^{0.18}
\end{aligned}
$$

where $\alpha_{0}=1.44$ for crushed or angular aggregate and 1 for rounded aggregate.

The fracture enegy results of the current study were plotted as a function of compressive strength as well as the wealth of fracture energy data avaliable in the literature [Bazant et al.1998; Arezoumandi et al. 2013; Ortega 2012]. The database shows a significant scatter of fracture energy test results, and it is hard to draw a defintive conclusion from the current test data. However, the HVFA-SCC test results fall within the upper portion of the data, as shown in Figure 10. Furthermore, Figure 11 shows that the fracture energy increases as compressive strength and tensile strength increases.

\begin{tabular}{|c|c|c|c|c|c|c|c|c|c|c|c|}
\hline \multirow[t]{2}{*}{ Mix ID } & \multirow{2}{*}{$\begin{array}{c}f_{c}^{\prime} \\
\mathbf{M P a}\end{array}$} & \multirow{2}{*}{$\begin{array}{c}f t \\
\text { MPa }\end{array}$} & \multirow[t]{2}{*}{ E GPa } & \multirow{2}{*}{$\begin{array}{c}\text { Average } \\
\text { Peak } \\
\text { load KN }\end{array}$} & \multicolumn{4}{|c|}{$G_{F}(N / m)$} & \multirow{2}{*}{$\begin{array}{l}\text { Average } \\
G_{F}(N / m)\end{array}$} & \multirow{2}{*}{$\begin{array}{c}\text { CO } \\
\text { V } \\
(\%)\end{array}$} & \multirow{2}{*}{$\begin{array}{c}\mathbf{l}_{\text {ch }} \\
\mathbf{m m}\end{array}$} \\
\hline & & & & & Beam 1 & Beam 2 & Beam 3 & Beam 4 & & & \\
\hline Control-SCC & 57.3 & 4.3 & 32.4 & 13.5 & 220.3 & 252.5 & 221.7 & 228.1 & 230.7 & 6.5 & 404.2 \\
\hline HVFA-SCC 50 & 53.5 & 3.76 & 36.9 & 12 & 197.5 & 200.2 & 215.3 & 166.5 & 194.9 & 10.5 & 508.7 \\
\hline HVFA-SCC 60 & 45.9 & 2.97 & 35.7 & 10.97 & 131.6 & 142.2 & 190.7 & 191.1 & 163.9 & 19.2 & 663.4 \\
\hline HVFA-SCC 70 & 52.9 & 3.65 & 39.1 & 12.58 & 166.3 & 257 & 190.3 & 228.6 & 210.5 & 19.1 & 617.9 \\
\hline
\end{tabular}

Table 4. Value of Fracture Energy Measured from Beam Tested in All Mixes.

\begin{tabular}{|c|c|c|c|c|}
\hline & Control-SCC & HVFA-SCC 50 & HVFA-SCC 60 & HVFA-SCC 70 \\
\hline $\mathbf{f}_{\mathrm{c}}^{\prime}(\mathbf{M P a})$ & 57.3 & 53.5 & 45.9 & 52.9 \\
\hline$G_{F}($ Average $),(N / m)$ & 230.7 & 194.9 & 163.9 & 210.5 \\
\hline G $_{\mathrm{F}}$ (Bazant et al.), ( N/m) & 143.6 & 139.1 & 129.6 & 138.4 \\
\hline GF(CEB-FIP), (N/m) & 151.3 & 149.4 & 145.4 & 149.1 \\
\hline$\left[\mathrm{G}_{\mathrm{F}}(\mathrm{Test}) / \mathrm{G}_{\mathrm{F}}\right.$ (Bazant et al.)] & 1.6 & 1.4 & 1.3 & 1.5 \\
\hline$\left[G_{F}(\right.$ Test $\left.) / G_{F}(C E B-F I P)\right]$ & 1.5 & 1.3 & 1.1 & 1.4 \\
\hline
\end{tabular}

Table 5. Fracture Energy Results Based on Different Equations. 


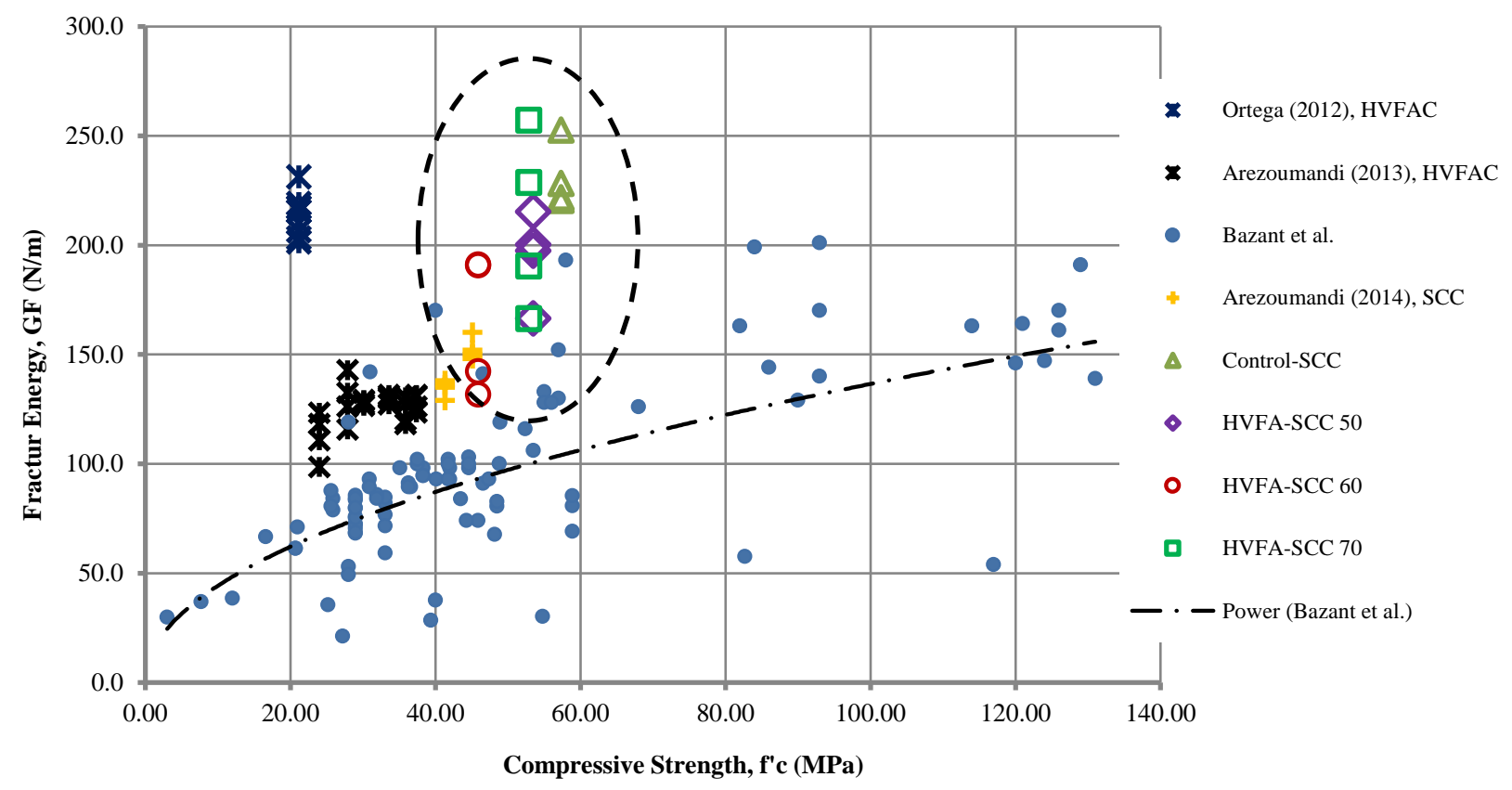

Figure 10. Fracture Energy vs. Compressive Strength.

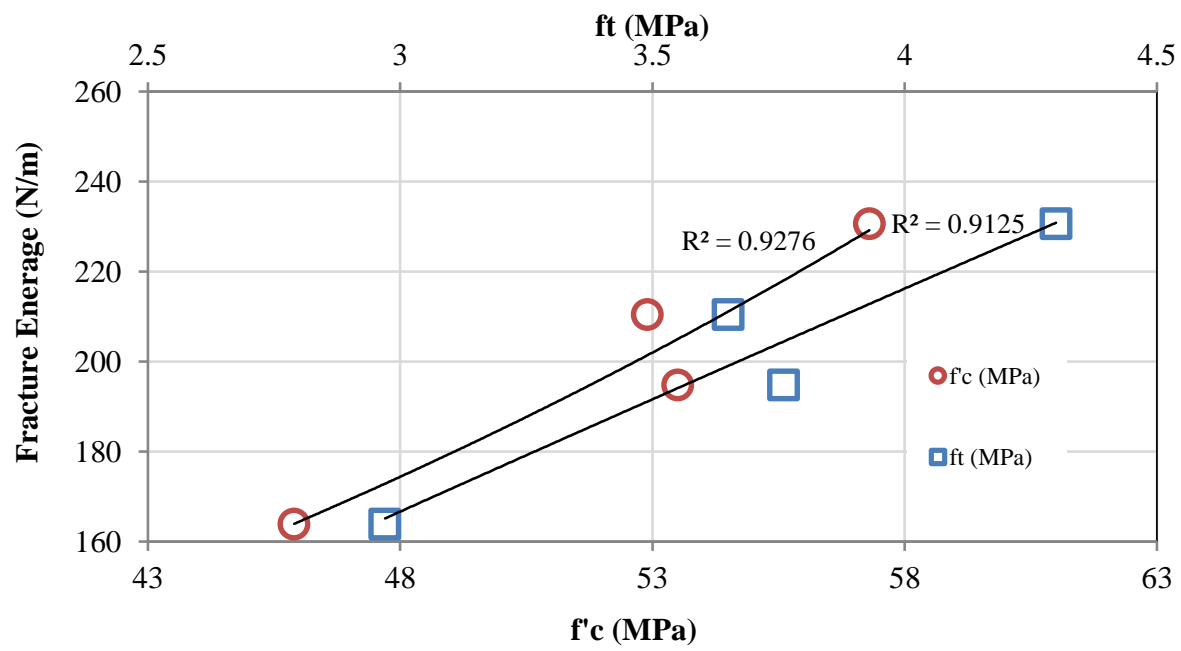

Figure 11. Variation of Fracture Energy with Compressive Strength and Tensile Strength.

\section{CONCLUSION}

Based on the results of this study, the following conclusions are presented:

- HVFA-SCC mixes exhibited satisfactory properties for most of the infrastructure applications.

- HVFA-SCC can promote the sustainability of concrete and cost efficiency.

- The mixtures with HVFA exhibited better rheological properties than the $100 \%$ cement mixture

- The $70 \%$ cement replacement mixture exhibited better mechanical properties than mixes with 50 and $60 \%$ replacement levels because the increase in hydrated lime increased the hydration 
activity of the fly ash.

- All HVFA-SCC mixes exhibited high brittleness than the $100 \%$ cement mix.

- Both Bazant and CEB-FIP equations underestimated the fracture energies of HVFA-SCC with predicted values ranging from 40 to $90 \%$ of the test values.

- The database showed a significant scatter of fracture energy test results making it difficult to draw a definitive conclusion from the current test data. However, the HVFA-SCC test results fall within the upper portion of the data.

\section{ACKNOWLEDGEMENTS}

The authors gratefully wish to acknowledge the financial support provided by the Missouri Department of Transportation (MoDOT) and the National University Transportation Center (NUTC) at the Missouri University of Science and Technology (Missouri S\&T).

\section{REFERENCES}

Alghazali H.H., Myers J.J. (2015) “Creep and Shrinkage of Ecological Self-Consolidating Concrete". Proceedings of Fifth PLSE2015 Conference, Brisbane, Australia.

Arezoumandi M., Volz J.S. (2013) "Effect of fly ash replacement on Fracture Behavior of concrete." Frontiers Journal of Structural and Civil Engineering, 7(4): 411-418

Bazant Z.P., Becq-Giraudon E. (2002). "Statistical prediction of fracture parameters of concrete and implications for choice of testing standards." Cement and Concrete Research Journal, 2002, 32(4): 529-556

Bazant Z.P., Planas J. (1998). "Fracture and size effect in concrete and other quasi-brittle materials." CRC Press.

Bilodeau A., Malhotra V.M. (2002). "High-volume fly ash system: Concrete solution for sustainable development." ACI Materials Journal, 2000, 97: 41-48.

Boden, T.A., Marland G., and Andres R.J. (2010). Global, Regional, and National Fossil-Fuel CO2 Emissions. Carbon Dioxide Information Analysis Center, Oak Ridge National Laboratory, U.S. Department of Energy, Oak Ridge, Tenn., U.S.A. doi 10.3334/CDIAC/00001_V2010

Brooks, J.J., and Sikharulidze, Z.D. (1992). "Strength and Fracture Energy of Concrete with and without Fly Ash Cured in Water at Different Constant Temperatures.” ACI Special Publication, Vol. 132, pp. 299-317.

CEB-FIP Model Code 2010-fib. 2012, 1: 120

Daczko J., Vachon M. (2006). "Self-Consolidating Concrete (SCC)." Significance of Tests and Properties of Concrete and Concrete- Making Materials STP 169D. ASTM International West Conshohocken, PA, 2006, 637-645. 
Enad M., Ibrahim A., El-Chabib H., and Patibandla V. C. (2013). "Self-Consolidating Concrete incorporating High Volume of Fly Ash, Slag, and recycled Asphalt Pavement”. International Journal of Concrete Structures and Materials. June 2013, Vol.7, No. 2, pp. 155-163

Hillerborg A., Modeer M., Petersson P.E. (1976). "Analysis of crack formation and crack growth in concrete by means of fracture mechanics and finite elements". Cement Concrete Research 1976;6: 773-82.

Khayat K.H., Mehdipour I. (2014). "Design and Performance of Crack-Free environmentally

Friendly Concrete: Crack-Free Eco-Crete", (Report NUTC R322). Missouri University of Science and Technology, Rolla, Missouri.

Lam L., Wong Y.L., Poon C.S. (1998). "Effect of fly ash and silica fume on compressive and fracture behaviors of concrete." Cement and Concrete Research, 1998, 28(2): 271-283

Ortega C.A. (2012) "Shear and Fracture Behavior of High-Volume Fly Ash Reinforced Concrete for

Sustainable Construction”. Ph.D. Dissertation. Missouri University of Science and Technology.

USA. 2012.

Ozawa K., Maekawa K., Kunishima M., Okamura H. (1989). "Development of High Performance Concrete Based on the Durability Design of Concrete Structures." In Proceedings of the Second

East-Asia and Pacific Conference on Structural Engineering and Construction (EASEC-2). 1989, $1: 445-450$.

Padevet P., and Zobla, O., (2011). "Fracture Energy of cement Paste with addition of the Fly Ash". $4^{\text {th }}$ International Conference Modelling of Mechanical and Mechatronic System 2011, technical University of Kosice. Kosice. Solovakia.

RILEM FMC-50 (1985). "Determination of the fracture energy of mortar and concrete by means of three-point bend tests on notched beams.” Material Struct 1985; 18(4):287-90.

The European Federation of National Trade Associations, EFNARC. (2005). "Specification and guidelines for self-compacting concrete." Association House, Farnham, U.K., 68.

Wong Y.L., Lam L., Poon C.S., Zhou F.P. (1999). "Properties of fly ash modified cement mortaraggregate interfaces." Cement and Concrete Research, 1999, 29(12): 1905-1913. 